\title{
Seeking for Solutions within a Project Setting
}

\author{
Peter Naudé · Stephan C. Henneberg • Stefanos Mouzas • \\ Carla Ramos $\cdot$ Andrew Graves $\cdot$ Valerie Crute
}

\begin{abstract}
There has been increasing attention focused on the importance of 'solution selling' in the often very close relationships that characterize business-to-business marketing. While an extant predominantly product-centric view of solutions prevails in the literature, this has recently been juxtaposed with a more process-oriented view. We review such a process-oriented solution model briefly, and focus on the managerial challenge of how firms make this process-oriented approach work in practice. We argue that, in parallel to adopting a process-oriented approach, companies also have to focus their attention specifically on how to mobilize the different parties in order to amalgamate the perspectives and orientations between the interacting counterparts. We propose an interaction process model of how this 'collective mind' is achieved, using as an example a study of the United Kingdom's Lean Aerospace Initiative (UK LAI), a large project with a specific solution in mind - improving the global competitiveness of the UK's Aerospace industry. We use our model to show how the three main groups of actors (Government bodies, four Universities, and the aerospace companies themselves) interact in their pursuit of co-creating their collective solutions.
\end{abstract}

Keywords: Solutions selling $\cdot$ Network insight $\cdot$ Project net $\cdot$ UK LAI

Published online: 28.08 .2009

(C) Gabler-Verlag 2009

P. Naudé $(\bowtie) \cdot$ S. C. Henneberg $\cdot$ C. Ramos

Manchester Business School, The University of Manchester, Booth Street West, Manchester, UK

e-mail: Peter.Naude@mbs.ac.uk

S. Mouzas

ManagementSchool, Lancaster University, Lancaster, UK

A. Graves · V. Crute

School of Management, University of Bath, Bath, UK 


\section{Introduction}

There is common acceptance in much of the business-to-business literature of the importance of 'solution selling', i.e. of the fact that many organisational buyers are in pursuit of solutions to complex problems, rather than looking to solve simplistic transaction-oriented issues (Brady et al. 2005; Sawhney 2006; Cova and Salle 2007). In a recent article Tuli et al. (2007) call for the existing product-centric view of customized and integrated goods and services offerings to be expanded into a more process oriented view, based upon deeper interactions between buyer and seller during the decision cycle. In this context, solutions can be seen to be a customized and integrated combination of both physical goods and services that aim to meet a particular customer's needs (Davies et al. 2006).

We introduce the viewpoint that seeking for solutions within complex, multi-company projects has moved beyond the buyer-seller process-centric view proposed by Tuli et al. (2007). Because increasingly complex solutions are necessary to succeed in systemic environments, these cannot be created solely by utilising the competences of either singular companies or buyer-seller dyads (Achrol and Kotler 1999). Rather, many 'solution strategies' depend on inter-organisational networks, these being increasingly complex multi-company network structures (Möller and Halinen 1999; Cova and Salle 2007). Often, such networks are instigated as a net of companies with the sole purposes of tackling complex problems, i.e. the solution network of companies can be described as a 'project net' (Möller and Svahn 2003). This can be described as a 'quasi-firm' characterized by loosely coupled inter-organizational relationships (Luke et al. 1989), in which there exists a minimal structure, and where there is usually no common ownership of member organizations, but with a high strategic purpose (i.e. between the members there is awareness of the need for shared inter-organizational goals).

In order to understand how these complex solutions are developed in such project or solution nets, we employ a case-based methodology similar to Kavanagh and Kelly (2002) to understand how companies deal with the multiple perspectives and expectations that the different actors have. We marry this to the more typical viewpoint of marketing within complex relationships and networks, specifically project networks, by way of conceptually grounding our analysis in the IMP (International Marketing and Purchasing) and project network literature (Håkansson and Snehota 1989; Cova and Salle 2007). A specific in-depth and longitudinal case study is used to exemplify the process of seeking for solutions within project networks. The UK's Lean Aerospace Initiative to improve the industry's lean methods in manufacturing and management was chosen for this purpose. Our case analysis shows that the process-oriented perspective of solution selling is still deficient in that it does not explain how it is that companies 'make it happen' - for this to occur, there has to be some mobilisation of the forces within the network that energize and focus their collective minds on achieving a particular outcome (Hadjikhani 1996; Günter and Bonaccorsi 1996). For this purpose, we propose in the final section an additional set of relational process activities running in parallel to the process-centric activities of Tuli et al. (2007). We argue that as part of this relational aspect, an amalgamation of the views of the different parties seeking a solution is pivotal for the expected outcome (solution) to happen. This amalgamation presumes that the involved parties are capable and willing to recognize the value of new knowledge, to take it on board and to use it in the creation of 
new business value. However, this absorptive capacity may be moderated by the context (Peters and Johnston 2009).

\section{The Marketing of Complex Solutions}

\section{Complex Solutions as a Bundled Offer or Process}

The current conceptual thinking about solution selling can be summarized by using an argument put forward by Tuli et al. (2007). They argue that the traditional product-centric view of selling solutions to customers which involves the customisation and bundling (i.e. integration) of goods and services, is not comprehensive enough, as it represents an overwhelmingly seller-oriented viewpoint. Based on their qualitative analysis of buyer and seller expectations, they propose an alternative process-centric approach which the selling companies need to consider (see Fig. 1).

Rather than being focused just on the customisation and integration of goods and services, selling companies also need to focus upon three other process steps. The first of these is requirements definition. This is of importance as many customers do not fully understand their own needs, i.e. they have high needs uncertainty (Ford et al. 2001). Furthermore, the broader context of the buyer needs, both current and future, must be fully considered. Beyond the accepted role of customisation and integration, the selling company also needs to consider the deployment, i.e. the on-time, in-full delivery and possible installation of the promise. Tuli et al. (2007) note that it is often at this stage that the customer's real requirements emerge or are clarified, calling for on-site adaptations and the often in-depth involvement of staff from both counterparts. Finally, post-deployment support in the arena of solutions entails more than the supply of maintenance, repair, and operational provisions. It involves the on-going evaluation of the delivered solution and the continual seeking for better ways to solve current and emerging problems.

\section{Solution Processes and Interactions}

The process-oriented understanding of solution selling focuses on more fully understanding the interactions between the relevant actors involved - the sellers and buyers (Ford and Håkansson 2006). This means embracing a dyadic view. However, the interactions

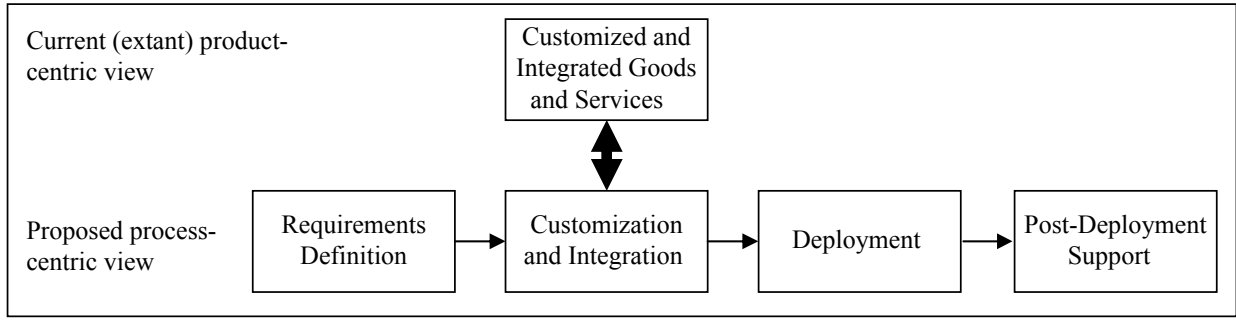

Fig. 1: A Comparison of Extant and Proposed Views of a Customer Solution (based on Tuli et al. 2007) 
underlying complex project settings can more usefully be seen as networking activities within complex systems of a number of actors (Cova and Salle 2007; Ford et al. 2003). Networking activities are thus based on the specific understanding by each actor of their own position, capability, power, etc. as well as that of other relevant players and their representation of the interaction characteristics of the project net within which the solution definition, provision and delivery is embedded (Tikkanen et al. 2007). We therefore posit that the challenge which multiple actors face in managing the joint delivery of complex project-based solutions is not merely that of managing process activities, but primarily that of amalgamating solution possibilities which do not exist in a transparent and concentrated form, but are dispersed bits of incomplete knowledge held by multiple actors (Mouzas et al. 2008). The creation of marketing solutions is a managerial challenge that requires developing insight within the solution complexity by amalgamating pieces of atomized and often 'interimistic' views through heedful multilateral interactions between the actors involved (Lambe et al. 2000). Such a managerial challenge, of creating solutions based on network insight, transcends the task-specific knowledge base of individually required solutions and is more likely to deliver the post-developmental interactions noted by Tuli et al. (2007). As such, this task is related to that of assimilating necessary capabilities through interactions with other actors, an activity which has been linked to absorptive capacity (Peters and Johnston 2009). The managers (or teams) involved that develop insight in dispersed solution environments such as project nets are those able to mobilize other actors involved in their projects in order to create better solutions for their customers and interaction partners. In fact, this means that often the distinction between 'buyers' and 'sellers' and their actions become problematic, with collaborative 'solution provision' representing relevant activities. The next section will provide some conceptual grounding, elaborating our theoretical framework, and detailing where we develop further the framework suggested by Tuli et al. (2007).

\section{Conceptual Grounding}

Businesses depend on the resources and capabilities of other businesses, and act within a web of complex interactions and relationships. This interactive structure exhibits characteristics of a network, i.e. a more organically grown web of companies (Håkansson and Snehota 1989; Axelsson 1992; Anderson et al. 1994; Ford et al. 2003), as well as of a net, i.e. a more intentionally created and managed constellation that comes together to solve particular solutions (Möller and Svahn 2003; Swart and Henneberg 2007). Such organisational network forms, or issue-based nets, are typified by co-operative relationships between the actors seeking to achieve a collectively recognized outcome (Brito 1999; Komppula 2000), although individual objectives and strategies might often vary between the players concerned (Mustikkamäki et al. 2001).

However, besides resources and capabilities, there exists another important dimension which needs to be investigated, especially with regard to understanding how multiple companies interact in order to mutually find and deliver solutions to complex problems: that of the dynamic managerial use of network pictures or individual cognitive maps (Möller and Halinen 1999; Henneberg et al. 2006). It can be shown that this issue is related to two challenges: first, how to 'integrate' network pictures from the subjective 
representation into an 'intersubjective' and 'objectified' construct that can be used for organisational (and inter-organisational) decision-making and option analysis (Meindl et al. 1994; Weick 1995). This is an issue which is clearly related to how learning takes place within a complex project team (Mäkinen 2002), as well as to firms' absorptive capacity that conditions learning and innovation in business networks (Cohen and Levinthal 1989; 1990; Peters and Johnston 2009). Second, while this integration (or 'amalgamation') is necessary (Mouzas and Naudé 2007), it is not sufficient to gain 'network insight.' Such insight can be defined as a distinct understanding of network and interaction characteristics (e.g. actors, interactions, resources, business logic, motivations, exchange processes) that is linked to sustainable competitive advantages which are embedded in the managerial activities of network organisations or the network itself (Meindl et al. 1994). Gaining network insight is in fact a complex and interactive process, based on the management of manifold exchanges and informed by heedful interactions (Weick and Roberts 1993). The creation of the 'network insight' is associated with what Peters and Johnston (2009) identified as being the new challenges for researchers' understanding of learning and knowledge management within value networks and that are associated with knowledge sharing and innovation. Based upon Haythornthwaite (2002), they argue that these challenges can be described as "the building of a repertoire of knowledge within the network, the collective sharing and interpretation of such knowledge, and the necessity to go beyond the interpretation of such knowledge, and the necessity to go beyond the consideration of information dissemination alone to include the consideration of mutual exchanges and interdependencies among learners" (p. 30). It is the special characteristics of this interactive element informing the process logic surrounding the seeking of solutions which we find missing from the Tuli et al. framework. While the process shown in Fig. 1 might work well in clearly defined buyer-seller dyads, it is not as neatly applicable in more complex business-to-business networks.

We use the model of developing network insight (Mouzas et al. 2008) as a starting point, based on which our discussion focuses specifically on understanding the processes that help or hinder the development of the joint delivery of solutions in project nets, what we term 'network insight'. This is concerned with how a project team put together by different organisations 'performs' in achieving, delivering, and disseminating (i.e. marketing) its 'solution' within the net (Cova and Salle 2007). In order to exemplify the interaction characteristics of gaining network insight in a solution net, we utilize a deep understanding of one specific market constellation of players working to achieve a solution to a complex problem, the case of the UK LAI project. Unlike most concentrated projects, this one is characterized by dispersed players and exchange structures which are changing over time. It was therefore chosen as a focal case because it can potentially shed light on the dynamics of the development of network insight in a complex environment while nevertheless being delineated clearly from its network horizon in the sense that the network boundaries are predefined within the project structure of the solution net (Holmen and Pedersen 2003). 


\section{The Quest for 'Leanness' and the UK LAI}

\section{UK LAI Context}

The United Kingdom's aerospace industry is the largest in Europe with capabilities across the whole spectrum of the aerospace activity chain including airframes, engines, aircraft equipment, avionic systems and weapons. The industry employs about half a million people, contributes about US\$12bn a year to the GDP, and accounts for some $7 \%$ of the country's exports (DTI 2003). It is supported by the Society of British Aerospace Companies (SBAC), the trade association of the UK Aerospace Industry that provides a framework of standards and co-ordinates the activities of its members to promote the competitiveness of the industry as a whole. In spite of its economic importance, the industry is faced with major strategic changes and dilemmas. The increasing degree of global (out)sourcing, environmental concerns, technological developments, politics, and the after-effects of 9-11 have all combined to result in global overcapacity, which in turn has detrimentally affected the United Kingdom industry's profitability, and also resulted in a decline in its global market share (Connor 2001).

The United Kingdom Lean Aerospace Initiative was designed to try to improve the competitiveness of the industry. Modelled on the US Lean Aerospace Initiative which was founded in 1993, the UK LAI was launched as a long-term, dispersed project starting in April 1998 with the objective of attempting to prioritize industry requirements for fostering 'lean' manufacturing and management structures. The project was established as a programmatic initiative by the SBAC to promote and apply lean techniques developed in other areas, most notably in the automotive industry (Womack et al., 1990). It is a project jointly sponsored by aerospace companies and the Engineering and Physical Sciences Research Council (EPSRC). From its inception, the UK LAI has been working closely with the Society of Motor Manufacturers and Traders (SMMT) and the US Lean Aerospace Initiative (based at the Massachusetts Institute of Technology - see http://lean.mit. edu) to identify best practices and to facilitate its application in the UK. As a dispersed project, it consists of three different sets of main partners: researchers at four different universities, government officers (such as the Department of Trade and Industry, and the Ministry of Defence) plus some 15 different companies that had chosen to get involved. The ultimate goal of the project is that "total product costs will be reduced throughout the supply chain and across product life-cycles, as a result of the adoption of lean thinking" (Ward and Graves 2004, p. 13).

\section{Project Organisation}

The UK LAI is organized around specific project themes that are dominated and managed by committees. These are staffed by the leading UK aerospace companies plus some smaller SMEs. Participants in these committees include the research partners and government officers, managed by a programme manager seconded from industry. These committees are charged with developing certain 'lean' concepts and tools, and of subsequently disseminating this knowledge to the client companies who are then, together with the appropriate governmental organisations, expected to implement the lean prin- 


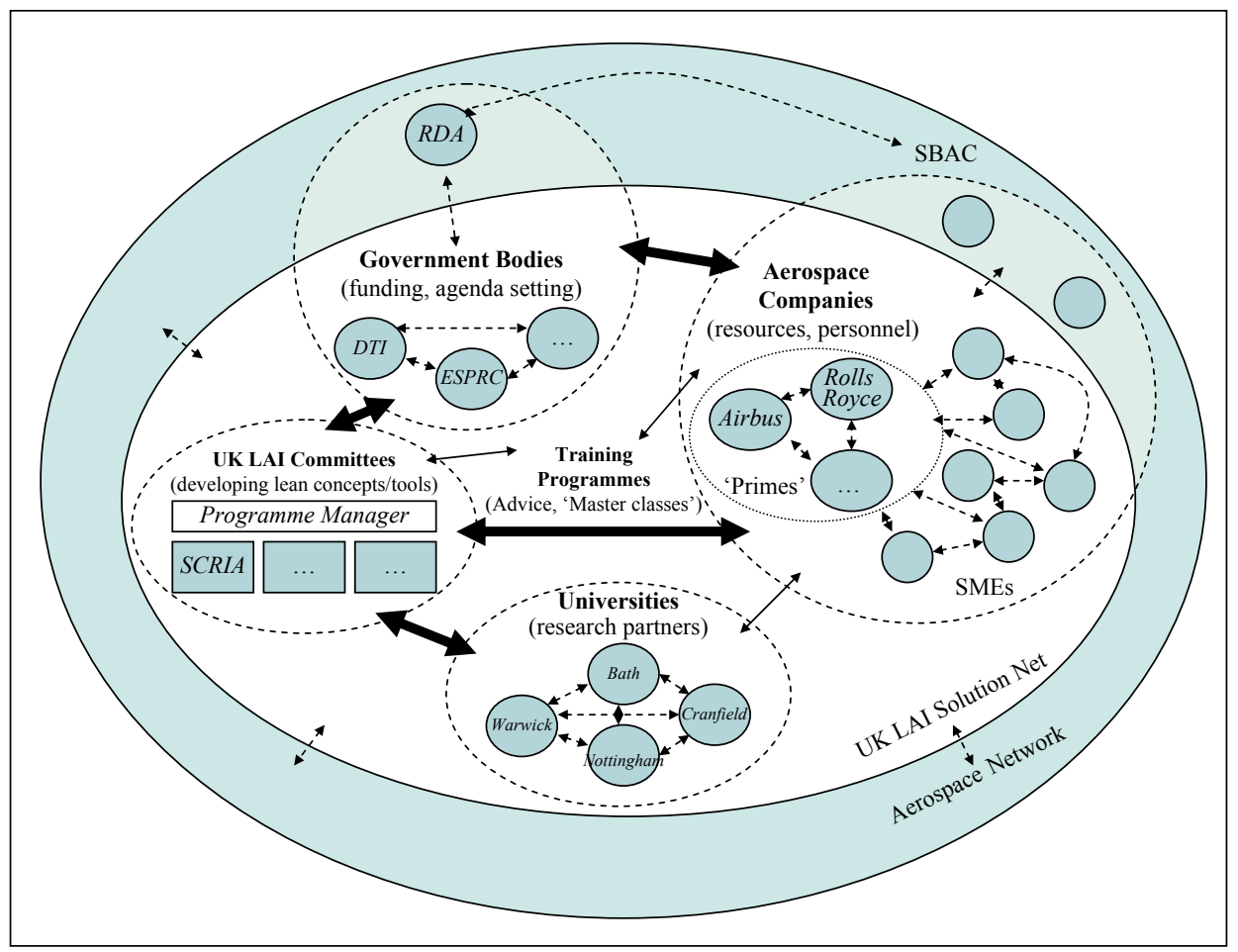

Note: $\mathrm{RDA}=$ Regional Development Agency; DTI = Department for Trade and Industry; EPSRC $=$ Engineering and Physical Science Research Council; SBAC $=$ Society of British Aerospace Companies, SCRIA = Supply Chain Relationship Industry Association

Fig. 2: UK LAI Solution Net (schematic representation)

ciples within their companies as well as with their exchange partners, i.e. the overall aerospace network. Moreover, the UK LAI runs training workshops and best practice programmes ('Master classes') which explore a variety of lean practices, focusing on the skills required for their successful implementation. A schematic overview of the UK LAI solution net is provided in Fig. 2.

\section{Thinking 'Lean'}

In general, lean programs were well established and accepted in many industries such as the automotive industry and also within manufacturer-retailer networks prior to the start of the UK LAI project (Womack et al. 1990; Lamming 1993; 1996; Fernie 1995; Mouzas and Araujo 2000). The essence of lean supply is to separate the production system from the network governance system (Johanson and Mattsson 1992) and so to focus on the most efficient means of delivering value to the ultimate consumer. Lamming (1996) describes the aims of lean supply as follows: "In lean supply, the entire flow from raw materials to consumer is considered as an integrated whole. Interfaces between stages (i.e. between 
companies - suppliers and customers) are thus seen as artificial-created not as natural transformation stages in the development or addition of value, but as a result of the economic arrangement of assets governed by many other factors, for example labour skills, convenient configurations of technology or geographical location of raw materials. The fundamental principle of lean supply is that the effects of costs associated with less than perfect execution of a sub-process are not limited to the location of the execution. This is a fundamental point since lean supply does not recognize the traditional positions of customer and supplier, which tend to obscure the central quest for the removal of waste" (187).

As described above, the UK LAI can be characterized as a long-term and complex search for solutions, aimed at delivering holistic change in the area of lean supply to the 'sponsoring' network (the UK aerospace industry as organized by the Society of British Aerospace Companies). As such this project is not unique: Buzzel and Ortmeyer's (1995) research into projects in manufacturer-retailer networks in the USA identified a number of change initiatives in areas such as electronic data interchange, new product development, product assortment planning and joint sales promotion. As in the case of lean supply, in the retailing sector there have been important developments centred on increasing the efficiency of manufacturer-retailer networks, eliminating waste and improving informational, monetary and physical flows in the network, from the production line of manufacturers to the shelves of retailers. In the words of Buzzell and Ortmeyer (1995), these arrangements . ".. seek to achieve some of the efficiencies of vertically integrated systems without common ownership" (p. 86). Womack and Jones (2005) have summarized such efforts under the concept of 'lean solutions'. This aim resembles vertical network structures as analysed by Achrol and Kotler (1999). Lean supply projects as solution selling open up the whole supply chain for scrutiny, and each linkage and network exchange is carefully examined with a special emphasis on delivery and stock replenishment, price management and promotions, trade conditions and allowances, as well as communication and information systems for order processing and billing. Hence, the implementation of lean program concepts rests upon a different conception of the inter-organisational business network and of the role of each actor in the value-creating system (Parolini 1999). Lean programs require a mode of thinking geared to the analysis of activities with little respect for formal, legal boundaries between firms and seek to transform and expand performance and accounting measures to the sphere of inter-organisational relationships (Mouzas and Araujo 2000).

\section{Research Method}

Our research sought to understand the interaction characteristics between the various actors, specifically regarding their combining of individual insights in order to develop joint solutions. The methodology used does not consist of the subjective solution views of individual project managers, but is grounded in the practice of inter-firm exchange (i.e. the amalgamation process of interactions which causes, if successful, overlapping representations of options and solutions). During our interviews, we operationalized the concept of 'developing network insight' by bearing in mind both the process-centric view 
of Tuli et al. (2007) but also sought to take a wider network perspective based upon Mouzas et al. (2008). We used this twin approach to develop our understanding of how companies mobilize their buying/supplying counterparts and develop their collective network insight in such complex environments, where even the definition of who is buyer and who is seller is not clear.

Towards the end of 2004, we started to study the UK LAI research team by utilizing the concept of network insight. In-depth interviews were used, with multiple interviews with 10 respondents used to ensure triangulation, covering different hierarchy and functional levels within the solution network (Janesick 1994). Such a case study method has been advocated to understand network structures (Halinen and Törnroos 2005). The interviews and qualitative analysis was conducted by five researchers. Primary data on actors' network pictures was collected first by visually eliciting respondents' representations of the network; respondents were asked to represent on an A0 sheet how they perceived their business surroundings. After providing the representation of their network, they were asked to explain what they had represented as well as to point out the reasons why they had represented it in those terms. This was complemented by a semi-structured interview, with respondents being asked to describe aspects of their business surrounding that were considered relevant for our analysis and that they had not included in their representation of their surroundings. For example, if a respondent did not incorporate in his/her representation the dynamics of the project evolution in time, this would be one of the aspects addressed in the semi-structured interview. This interlacing of visual and textual data analysis (Meyer 1991; Tufte 1983; Zuboff 1989; Ramos et al. 2005; Henneberg et al. 2006) helped researchers understanding respondents' representations, and seeking clarification from the respondents on 'how the system worked'. On the basis of this, our underlying model was recursively redefined but is still morphologically similar to the theoretical concept of network insight from which it was derived (Mouzas et al. 2008). In these different eliciting steps we mainly followed Ramos et al. (2005) and Henneberg et al. (2009).

Based on our initial round of analysis, the data concerning the empirical constructs were analysed and discussed between the researchers. This was done to check for redundant data categories. However, all expected data categories were present in the interview material. This initiated a second and follow-up round of interviews which also incorporated exploratory questions regarding hypotheses that had been developed for the derived constructs (barriers to amalgamation and project insight respectively). Our understanding of the empirical data as well as our hypotheses regarding the derived constructs was then used as the input for another clarification round of interviews that focused on verification and deepening of the understanding of specific topics (Halinen and Törnroos 2005).

\section{Analysis}

\section{Requirements Definition}

As might be expected, we found that a variety of different perceptions were held about the activities of the various parties involved within the UK LAI, and the fact that differ- 
ent parties were seeking different outcomes. These differences covered descriptive issues such as the activities, exchanges, etc. that happened, but also judgements for example about expectations, or centres of power. While there were instances where some form of unanimity seemed to exist (e.g. with regard to the net members), in others competing perceptions were held. Obviously, no one of these can put forward as representing the 'objective' or 'correct view'. Instead, we discuss below some of the different perceptions held, recognising that the issues are often highly interrelated and not as independent as might be implied.

There was clear evidence of what could be seen as manifold rationalities, although whether this was entirely beneficial is a moot point. On the positive side, it was accepted that "there need to be different things going on at different times - we are all at a different stage of implementing lean" (Committee Project Manager). Another aspect of this was the seemingly divergent but often unintentionally complementary pursuit of different goals, such as academic papers (academic institutions) and improvements in cash flow positions (aerospace manufacturers). On the negative side, there were also clearly incidences where the different rationalities or 'requirements definition' seemed to hinder rather than aid progress. The most common occurrence of this was the understanding of the role of finance within the project: the companies tend to be profit oriented and therefore base decisions on 'business cases', whereas the universities work to annual budgets, which tends to hamper recruitment and hence the research process.

\section{Customisation and Integration}

We found that there was broad acceptance by all actors involved that the problem solving environment in which they found themselves called for change - the range of strategic changes identified earlier meant that many firms were operating at well below their desired levels of profitability. While there was consensus, or an amalgamation of viewpoints, on the broader environment and on the logic underlying the project, the self perceptions of some of the players, the historical influences of some of the larger players, and the impressions that some actors had, tended to vary widely, as described below.

The need for a common goal among the actors involved is usually taken for granted in the solution management literature, as reflected by the 'requirements definition' element in Fig. 1. However, what we found was often a lack of common perspective which continued throughout the period analysed. Rather, it seemed to be a truer reflection that the work of 'providing solutions' in reality consists of many subprojects which to some extent achieved integration and customization within these subprojects, and that certain players saw minimal integration between some of the parts (this is true in the case of UK LAI for 'sellers' such as universities and committees as well as for 'buyers' such as the aerospace companies). This is perhaps to be expected, where aspects of the work may be handled strategically by senior managers, and other operational aspects handled by more junior staff - reflected in the 'contingent hierarchy' discussed by Tuli et al. (2007).

A positive facet of the UK LAI is the very proactive manner in which multilateral exchanges were encouraged and supported. As mentioned above, this occurred at all levels: from periodic strategic reviews by the senior managers and researchers, through to regular conferences arranged between the academic researchers and the managers in 
order to exchange research findings and to discuss future developments. In addition, six engineers employed by SBAC acted as 'roving ambassadors' to explain the benefits and help to implement lean practices in the companies involved. This encouraged cross-entity interactions and the closure of 'structural holes' in the interaction patterns of the net partners (Burt 1992).

\section{Deployment}

In our case, the seeking for solutions seemed to be hampered by the number of players involved, their roles, and their respective sizes. Although most respondents perceived a clearly delineated net of actors who were involved, it became clear that the UK LAI is a solution-seeking project without clear boundaries or morphology. While the companies involved are clearly identifiable, there are many other companies and also other organisations (the Ministry of Defence, MIT, other Universities) that lie on the periphery and whose role is not clear. In addition, there are regional sub-clusters within the project, implying that different groups may be moving ahead faster or slower than other parts of the project. The project was also hampered by the movement of individual people: university researchers being replaced by others, and also people moving between the companies involved, both of which combined to make the amalgamation process far more difficult as it disrupted interaction patterns, especially strong ties (Granovetter 1973, 1985). In terms of the actors involved and their levels, the smaller companies were often concerned about the dominating role of the larger ones, feeling that they would be imposed upon. This aspect of the UK LAI seemed to hamper the efficient deployment of resources, and resulted in less amalgamation of their cognitive perceptions.

\section{Post-Deployment Support}

Given the multiplicity of sub-projects referred to above, it is not surprising to find that there was a certain lack of clarity in the minds of the different actors about just what the project was trying to achieve, or indeed for whom. The 'solution' around which the project was constituted remained opaque, even over time, and was not clarified. The potentially dominating role of the larger companies was referred to above, but the countervailing position was one of arguing that "the larger companies don't need the UK LAI. They know more about 6 Sigma and lean than anyone else in the world, and we can teach them nothing. They are just here as figureheads, because without them being part, we will not get the smaller ones involved" (Research Fellow, Participating University). In addition, it was generally recognized that there could not be one measurable outcome. Outcomes exist at different levels for the different actors involved. Given that funding comes from the Government via the EPSRC, one measurable outcome is in terms of published academic material as well as reports to Government. For the companies, on the other hand, outcomes have more to do with cash flow, reduced waste, and the benefits associated with reducing time.

The issue of how time was dealt with certainly seemed to affect the extent to which there was development of joint solution insights. On the positive side, there was acceptance of developmental time and the need to have differing perspectives: "implementing 
lean can take a company 30 years to achieve, and we must remember that. But we also have to do things tomorrow, to plan a meeting to discuss our joint findings and developments next month to make sure that everyone stays on the road" (Research Fellow, Participating University). On the negative side, however, we found that the companies involved were accepting of the fact that this long term perspective was required, whereas the universities were driven by funding that often lasted only a few months into the future, and for whom this longer time frame was largely irrelevant.

In our case study, we detected some indicators that joint insights had been achieved. There seemed to be a general consensus that the project had generated something positive, that the United Kingdom's Aerospace Industry was now more competitive than it has been before the start of the project. Implementing lean practices in the companies has had a positive economic outcome. However, questions remained about the extent to which the project might have done even better. During the research, doubt about whether or not funding for the project would continue surfaced from many respondents. As one respondent commented "We have failed. We didn't tell them (i.e. the Government funding body) what we would do next. We chose the wrong people to do the lobbying, gave the wrong message" (Research Leader of Participating University). Another commented "There are over 200 companies involved in the industry in the UK. And we have got only about 20 involved in the project - it could have been even bigger and better" (Committee Project Manager).

There was evidence that the companies involved in the UK LAI traversed increasingly towards a concern with efficiency (reducing costs and time, and improving supply processes) and less withimproving solution effectiveness in the marketplace. To quote a respondent, "the project's focus on 'lean'has not contributed to the creation of new sources of value within the industry" (Research Fellow, Participating University). The creation of new sources of value within the industry requires project managers to escape the narrow focus on task-specific requirements of existing projects. It requires multilateral and heedful interactions that embrace inherent manifold rationalities. Our model would suggest that the lack of creation of new sources of value is a result of the fact that while there were manifold rationalities being utilized, there was no way in which these were consistently transformed into a collective mind - the different rationalities retained their individual identities and no collective or uniform mindset emerged. In other words, the underlying network pictures of all relevant actors, while different at the beginning of the project, did not materially converge or interact sufficiently. This, in turn, meant that while some insight unquestionably existed and resulted in specific economic benefits to some of the players, the project as an entity did not produce the level of collective insight that the industry may have wished for. These results are in line with concepts from a Social Network Analysis viewpoint (Burt 1992; Wasserman and Faust 1994), looking at the strength of the ties between the participants: while there were some strong ties between the 'core' participants (the formation of which was not helped by the frequent rotation of personnel), there were many at the periphery that had far weaker and simply functional allegiance to the manifold rationalities of the major players. It might be argued that this was a 'structure' more suited to a 'doing and implementing project network' than to a 'creative and new thinking network' such as a solution net. 


\section{Relational Implications}

The problem in complex project settings such as the UK LAI, is that inherent solutions do not exist in a transparent and concentrated form, but are dispersed bits of incomplete knowledge held by multiple actors. This suggests to us that the proposed process-centric view as suggested by Tuli et al. (2007) has shortcomings in that it focuses on what needs to be done in terms of (dyadic) process steps, but does not identify sufficiently how this might be accomplished in terms of interaction patterns involving many different actors. Understanding how it is that the multiple parties that deliver complex solutions, with their differing perspectives and objectives, act so as to combine their perceptions in order to deliver a common value proposition, is still in its infancy. While network pictures or similar constructs of cognitive antecedents of networking activities have become important research foci for the IMP Group and others working in related areas, our understanding of the managerial use of these cognitive concepts is still limited (Håkansson and Snehota 1995; Dyer and Singh 1998). Therefore, this research contributes to a hitherto underresearched area, linking it to the issue of selling complex solutions in a complex businessto-business environment.

The potential benefits of projects do not come only from the idiosyncratic capabilities of the selling firms or the participating companies in a solution net, but are essentially derived from membership in communities of business relationships (Komppula 2000; Mäkinen 2002). These aspects become even more important when companies participate in complex multi-organisational projects. They need to escape the narrow boundaries of their own cognitive pictures and open themselves by building new relationships and heedful interactions with other actors. Based upon the empirical model of developing network insight, and on the testing of that model through an examination of the UK LAI, we believe that it offers a structured way for both managers and researchers to examine the complex but purposive nets in which they often find themselves working. However, our findings imply that this means supplementing a purely process-oriented perspective of solution selling with a parallel relational view taking into account interaction patterns (Sharma et al. 2002). Thus, we propose an enriched model as shown in Fig. 3 as a way of better understanding the managerial process and relational requirements of solution selling.

The relational process model indicates ways in which network insight can be developed in parallel to the extended solution selling process as introduced by Tuli et al. (2007). In order for the solution requirements to be clearly defined by the various parties (direct as well as indirect actors), there has to be some recognition of the assumptions and cognitions of the other actors involved. This is best done by utilising a network picture methodology (Henneberg et al. 2006; Ford and Ramos 2006), especially by focussing on the images, identities, and impressions held by individual managers or actors. This must be followed by manifold interactions resulting in a portfolio of strong and weak ties, focussing on amalgamating the differing views of the actors involved, a necessary precursor to there being any development of the 'collective mind' (Weick and Roberts 1993). This will allow for the customization and integration of solutions, and is a precursor for the deployment step which needs to be based on network insight, i.e. an inter-subjective cognitive 


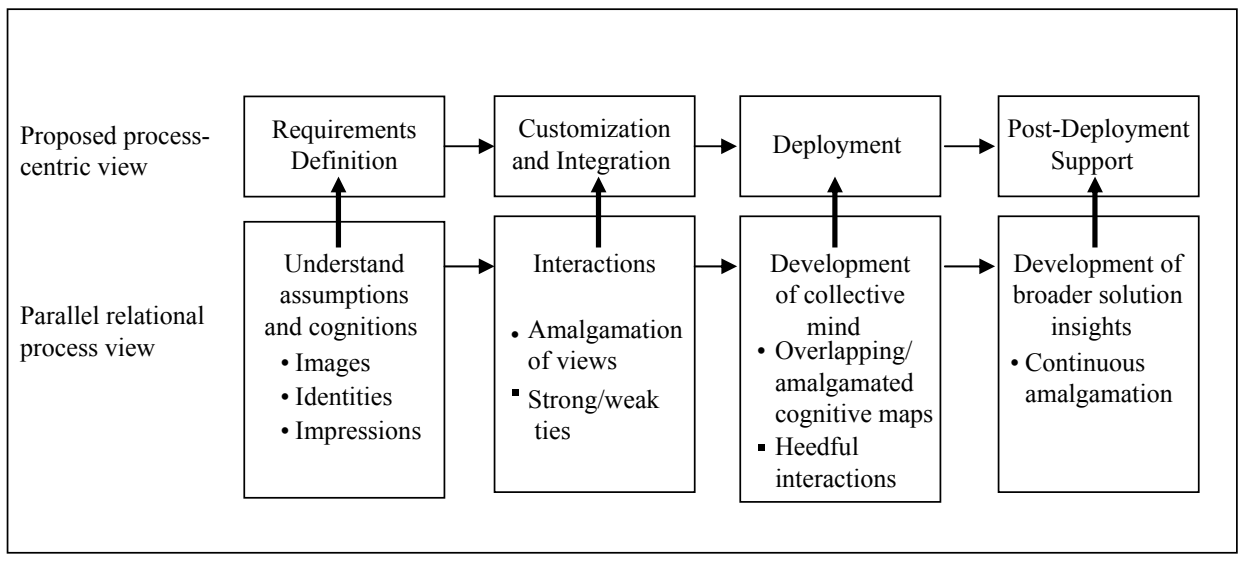

Fig. 3: Developing Joint Solutions in a Multiple Participant Environment

congruence of network pictures. It is only once this is done, that the broader insights will develop that are required for the optimization of solutions in the post-deployment phase.

The definition of requirements needs a parallel phase involving a development of an understanding of the assumptions and cognitions of the different parties. It is too simplistic to assume that all parties are united in achieving a common goal - something that is far more likely to occur in the more simple case of dealing with just dyadic partners. As shown in the UK LAI case, we believe that developing this understanding of the other parties' assumptions and cognitions is most readily done by trying to understand the images, identities and impressions of the range of other parties involved: what are their network pictures that inform their actions?

The process should start with an examination of what can be thought of as the input data for each of the actors involved. This includes understanding not just the actors, activities, and resources involved in the work, but needs to build on developing an understanding of the past histories, future expectations, and different perspectives that the various partied have of both themselves and their numerous counterparts (Henneberg et al. 2006). It is only in this way that the assumptions and cognitions of the other parties will be understood, which we believe to be a key antecedent of fully understanding the requirements definition.

In order for the second stage, that of customization and integration to take place, there has to be some amalgamation of views, whereby the different actors interact in order to reach agreement. This examines the way in which the different actors combine and exchange their individual and idiosyncratic views of the world, incorporating both their individual and organisational requirements, in such a way as to move the project ahead. This is an important and under-researched area, understanding how the network pictures of the various participants are combined to reach managerial consensus - explicitly or more likely implicitly - in a manner that enables managerial decisions to be taken. We propose that one way of studying this issue is by examining how the interactions between actors in the net take place, the tools and techniques that are used to reach consensus, and by understanding how that consensus is subsequently codified (Öberg et al. 2007). In our 
UK LAI case, the interaction and search for resolution was handled in different ways, such as regular meetings to agree on measurement approaches, and the diffusion of initial results through the 'lean master classes.' This is likely to be based on the extent to which ties between the different actors can be exploited to their common advantage: the looser the ties, the more likely it is that there will be multiple outcomes (as in the case of the manufacturing companies and the Universities above).

The way in which the amalgamation was sought within the UK LAI was particularly interesting. In this complex environment, the strength of the ties between the different actors, and hence the ease and clarity with which broader solution insights can be developed, clearly varied. The UK LAI, through their various committee structures, could be argued to have a rather clearly defined core team of actors involved, supported on the periphery by many other parties. Those on the periphery obviously build strong as well as weak ties with the 'core' team, dependent on their own objectives and manifold rationalities. However, between the core and the peripheral groups, as well as between the different peripheral groups, there were only weak (i.e. functional) ties. This is not a particularly optimal structure, as it hinders the degree of coordination, the ease of synthesizing different views, as well as cross-pollination in terms of the flow of new and creative thinking (Burt 1992; Borgatti and Foster 2003; Cross et al. 2002).

The third stage, that of deployment, must run in parallel with some degree of development of a collective mindset. This requires exploring the extent to which there are overlaps between, or possible amalgamations of, the network pictures of the different actors. But this is still only a prerequisite for the deployment of resources - it has to be followed by what we term 'heedful interactions,' those which go beyond the task-specific knowledge base of managerial cognition, and lead to objectified organizational learning within the wider project, thereby raising the possibilities of wider dissemination to other parties (as took place via the academics' interactions at conferences and through the Master classes).

Finally, for there to be on-going post-development support, we would argue that there has to be a parallel process seeking to develop broader solution insights in to the future, based upon the collective needs and insights of all parties involved. This requires the active management of continuing efforts to amalgamate the network pictures of the different actors in the network, to keep them 'on track' in terms of continuing to work together. This needs to be an ongoing activity within complex solution nets. It is worth mentioning that the development of network insights for a particular project is believed to facilitate actors' scope of action and increases their potential, between projects and in future projects. It is therefore relevant in defining the milieu in which actors operate (Cova et al. 1996), particularly the mechanisms to access other actors' fact-based information, data and knowledge; these mechanisms can be adjusted to other projects and/or actors. However, overuse of these mechanisms can cause too much overlap of the beliefs within and between companies, and thus create ossification (Porac et al. 1989).

The suggested parallel relational process view which enriches the extended solution selling process as introduced by Tuli et al. (2007) can be understood as outlining mechanisms which enhance the development of network insights within the project net. This amalgamation process allows managers to develop an objectified (i.e. intersubjective) perspective of the situation in which they are involved, developing knowledge of the 
context in which they are embedded (Mouzas et al. 2008). The process through which managers can generate network 'insight' can be compared to that of creating a 'collective mind' (Weick and Roberts 1993; Wiley 1988) and 'collective knowledge' (Grant 1996; Grant and Baden-Fuller 2004). It is worth mentioning that the 'heedful' interactions underlying the creation of such a collective mind or 'insight' results in a transfer of knowledge between actors, changing actors' minds. The collective mind is not fully represented in one single individual, being only partially overlapping between individuals (Mouzas et al. 2008). Diversity is acknowledged as a positive element in the creation of a collective mind situation (Weick and Roberts 1993); therefore, the insight does not imply cognitive alignment or overlapping of actors' network pictures, instead representing a chance for managers to assure on-going access to other actors' informational resources and thus making tacit assumptions explicit and objectified. The amalgamation process that is implied in the development of network insight includes intra-organisational but also inter-organisational exchanges as part of the solution network of companies, i.e. the 'project net'.

In the analysis and discussion (i.e. relational implications) sections, we began by describing and exploring what we believe 'worked' or 'did not work' within the 'project net' analyzed with this paper. Moreover, we made some suggestions regarding the measures that could (and that we believe should) be implemented by the managers involved to assure the development of network 'insight'. We would like to clarify that it is not intended to imply some form of 'optimum performance' of the network; instead, we are building on the empirical findings that point out to the negative aspects associated with the absence of network insight in order to make suggestions about how companies could develop mechanisms to achieve such insight, thus contributing to a better functioning of this particular 'project net' by more 'efficient' and successful development of joint solutions.

\section{Conclusions}

The genesis of this article was the proposal by Tuli et al. (2007) that, within business-tobusiness marketing of solutions, a process-centric view of the interaction between buyer and seller should be adopted, rather than the more prevalent and traditional product-centric view. This article attempts firstly to apply this model, and secondly to develop it further into a more expansive approach, by analysing an environment in which multiple stakeholders come together to seek for solutions within complex projects.

Our analysis of the UK LAI project net allows us to propose a structured approach with additional relational process variables (shown in Fig. 3) in order to develop an understanding of how to manage the search for solutions in such complex settings. The implications of the model, and confirmed through our case study, are that managers involved in such networks (and also researchers trying to understand the process characteristics involved) need to consider some parallel relational processes complementary to the process-centric view, and we offer this model as a parsimonious way in which to focus researchers' and managers' views when developing their understanding of how such complex projects 
unfold. Thus, this paper also reflects a contribution to the existing literature on 'quasi firms', i.e. a specific strategic form of inter-organizational relations (Luke et al. 1989).

The model uses as its starting point the four-phase model of Tuli et al. (2007), and shows how in each of the phases there is a requirement to ask additional questions, and to collect additional information. The managerial implications of such an approach appear at first to be largely negative, in that we are calling for more time and effort to be spent on the collection of information from the different parties involved. Indeed, identifying who to speak to and hence where exactly the border of the relevant network picture might be, is a moot point (Ford et al. 2003; Henneberg et al. 2006). As shown in Fig. 2, the UK LAI network is simply a subset of the larger network of Aerospace companies, any one of whom could arguably be said to influence what happens within the UK LAI project. However, the counter argument to this is that to not adopt the broader viewpoint exemplified by Fig. 3 is far more likely to result in project failure. We would suggest that it is only by taking a parallel relational process view that chances of success for individual project network actors as well as the network itself can be increased.

In our research, we did not consider the milieu level of analysis, but instead solely the in-project level. Cova et al. (1996) argue that in order to be able to anticipate their counterparts' needs, supplier firms selling capital projects ought to consider their portfolio of projects and not solely a single project. This would imply moving from a supplier/customer transactional in-project perspective to a supplier/customer relational perspective, including aspects of future projects. We decided not to include the milieu level of analysis to restrict the increase of complexity that would result from considering not only the actors and relationships involved in a particular project (i.e. in our example, the UK LAI), but instead the whole territorial network for a particular sector (Cova et al. 1994), i.e. the aerospace industry. However, future research into solutions within project networks needs to understand the relationship between different projects as part of an overall embedding milieu. Furthermore, our model needs to be tested against other conceptual frameworks to provide a more detailed understanding of the interaction process of solution selling. One such framework could be provided by the recent work on theories of communication networks (Monge and Contractor 2003), another framework is that of absorptive capacity (Zahra and George 2002), especially adapted to the network perspective (Peters and Johnston 2009). This would allow for a better understanding how the parallel relational process view of solution selling as proposed in our study works within a contingency framework, e.g. including power relationships or aspects of homophily in amalgamating network pictures.

\section{References}

Achrol RS, Kotler P (1999) Marketing in the network economy. J Mark 63(Special Issue): $146-163$

Anderson JC, Håkansson H, Johanson J (1994) Dyadic business relationships within a business network context. J Mark 58:1-15

Axelsson B (1992) Corporate strategy models and networks - diverging perspectives. In: Axelsson B, Easton G (eds) Industrial networks. A new view of reality, Routledge, pp 184-204 
Borgatti S, Foster P (2003) The network paradigm in organizational research: A review and typology. J Manag 29(6):991-1013

Brady T, Davies A, Gann D (2005) Creating value by delivering integrated solutions. Int J Project Manag 23(July):360-365

Brito C (1999) Issue-based nets: A methodological approach to the sampling issue in Industrial Networks Research. Qual Market Res 2(2):92-102

Burt RS (1992) Structural holes: The social structure of competition. Harvard University Press, Cambridge

Buzzell RD, Ortmeyer G (1995) Channel partnerships streamline distribution. Sloan Manag Rev 36(3):85-96

Cohen D, Levinthal D (1989) Innovation and learning: The two faces of R\&D. Econ J 99:569-596

Cohen D, Levinthal D (1990) Absorptive capacity: A new perspective on learning and innovation. Adm Sci Q 35:128-152

Connor P (2001) An assessment and comparison of the levels of marketing effectiveness in the UK Aerospace Industry. Int J Aerospace Manag 1(1):9-22

Cova B, Mazet F, Salle R (1994) From competitive tendering to strategic marketing: An inductive approach to theory-building. J Strateg Mark 2:1-19

Cova B, Mazet F, Salle R (1996) Milieu as a pertinent unit of analysis in project marketing. Int Bus Rev 5(6):647-664

Cova B, Salle R (2007) Introduction to the IMM special issue on 'Project marketing and the marketing of solutions': A comprehensive approach to project marketing and the marketing of solutions. Ind Mark Manag 36:138-146

Cross R, Borgatti S, Parker A (2002) Making the invisible visible: Using social network analysis to support strategic collaboration. Calif Manage Rev 44:25-46

Davies A, Brady T, Hobday M (2006) Charting a path toward integrated solutions. Sloan Manag Rev 47:39-48

DTI (2003) An independent report on the future of the UK Aerospace Industry. Department for Trade and Industry, Government Printer

Dyer JD, Singh H (1998) The relational view: Cooperative strategy and sources of interorganizational competitive advantage. Acad Manag Rev 23(4):660-679

Fernie J (1995) International comparisons of supply chain management in grocery retailing. Service Ind J 15(4):134-147

Ford D, Berthon P, Brown S et al (2001) The business marketing course: Managing in complex networks. Wiley, Chichester

Ford D, Gadde LE, Håkansson H, Snehota I (2003) Managing business networks. Wiley, Chichester

Ford D, Håkansson H (2006) The idea of interaction.” IMP J 1(1):4-27

Ford D, Ramos C (2006) Network pictures: Conceptual development and preliminary findings. Paper presented at the 22nd IMP conference 5-6 September, Milan

Granovetter M (1973) The strength of weak ties. Am J Sociol 78(6):1360-1380

Granovetter M (1985) Economic action and social structure: A theory of embeddedness. Am J Sociol 91:481-510

Grant R (1996) Prospering in dynamically-competitive environments: Organisational capacity as knowledge integration. Organ Sci 7(4):375-387

Grant R, Baden-Fuller C (2004) A knowledge assessing theory of strategic alliances. J Manag Stud 41(1):61-84

Günter B, Bonaccorsi A (1996) Project marketing and systems selling - in search of frameworks and insights. Int Bus Rev 5(6):531-537

Hadjikhani A (1996) Project marketing and the management of discontinuity. Int Bus Rev 5(3):319-336 
Håkansson H, Snehota I (1989) No business is an Island: The network concept of business strategy. Scand J Manage 4(3): 187-200

Håkansson H, Snehota I (1995) Developing relationships in business networks. Routledge, London

Halinen A, Törnroos J-A (2005) Using case methods in the study of contemporary business networks. J Bus Res 58:1285-1297

Haythornthwaite C (2002) Building social networks via computer networks: Creating and sustaining distributed learning communities in building virtual communities. In: Renninger KA, Shumar W (eds) Learning and change in cyberspace. Cambridge University Press, Cambridge, pp 159-190

Henneberg S, Mouzas S, Naudé P (2006) Network pictures - concepts and representations. Europ J Mark 40(3/4):408-429

Henneberg S, Naudé P, Mouzas S (2009) Sense-making and management in business networks - some observations, considerations and a research agenda. Ind Mark Manag 3(2):91-113

Holmen E, Pedersen AC (2003) Strategizing through analyzing and influencing the network horizon. Ind Mark Manag 32(5):409-418

Janesick VJ (1994) The dance of qualitative research design. In: Denzin NK, Lincoln YS (eds) Handbook of qualitative research, Sage, Thousand Oaks, pp 209-219

Johanson J, Mattsson LG (1992) Positions and strategic action - an analytic framework. In: Axelsson B, Easton G (eds) Industrial networks. A new view of reality, Routledge, pp 204-217

Kavanagh D, Kelly S (2002) Sensemaking, safety, and situated communities in (con)temporary networks. J Bus Res 55:583-594

Komppula R (2000) The representative role of an issue-based net within a regional tourism network. Paper presented at the 16th IMP Conference. Bath, UK

Lambe C, Spekman R, Hunt S (2000) Interimistic relational exchange: Conceptualization and propositional development. J Acad Mark Sci 28(2):212-225

Lamming R (1993) Beyond partnership. Strategies for innovation and lean supply. Prentice-Hall, Hemel Hempstead

Lamming R (1996) Squaring lean supply with supply chain management. Int J Operations Prod Manag 16(2):183-196

Luke RD, Begun JW, Pointer DD (1989) Quasi firms: Strategic inter-organisational forms in the Health Care Industry. Acad Manag Rev 14(1):9-19

Mäkinen H (2002) Intra-firm and inter-firm learning in the context of start-up companies. Int J Entrepreneurship Innov 3(1):35-43

Meindl JR, Stubbart C, Porac JF (1994) Cognition within and between organizations: Five key questions. Organ Sci 5(3):289-293

Meyer A (1991) Visual data in organizational research. Organ Sci 2:218-236

Möller KK, Halinen A (1999) Business relationships and networks: Managerial challenge of network era. Ind Mark Manag 28:413-427

Möller K, Svahn S (2003) Managing strategic nets: A capability perspective. Mark Theory 3(2):209-234

Monge P, Contractor N (2003) Theories of communication networks. University Press, Oxford

Mouzas S, Araujo L (2000) Implementing programmatic initiatives in manufacturer-retailer networks. Ind Mark Manag 29(4):293-303

Mouzas S, Naudé P (2007) Network mobilizer. J Bus Ind Mark 22(1):62-71

Mouzas S, Henneberg S, Naudé P (2008) Developing network insight. Ind Mark Manag 37:167-180

Mustikkamäki N, Viljamaa K, Sotarauta M (2001) Urban networks - special or issue-based: Some reflections from finland. Paper prepared by the research unit for urban and regional development. University of Tampere, Tampere 
Öberg C, Henneberg S, Mouzas S (2007) Organisational manifestations of network pictures - concept and case evidence. Paper presented at the 3rd IMP workshop, Trondheim, May 2007

Parolini C (1999) The value net. Wiley, Chichester

Peters L, Johnston W (2009) Understanding absorptive capacity from a network perspective. J Bus Manag 3(1):29-50

Porac J, Thomas H, Baden-Fuller C (1989) Competitive groups as cognitive communities: The case of the scottish knitwear manufacturers. J Manag Stud 26(4):397-416

Ramos C, Naudé P, Ford D (2005) Developing network pictures as a conceptual device. 1st IMP meeting of the IMP journal, Oslo, Norway

Sawhney M (2006) Going beyond the product: Defining, designing, and delivering customer solutions. In Lusch R, Vargo S (eds) The service-dominant logic of marketing: Dialog, debate, and directions. M.E. Sharpe, New York, pp 365-389

Sharma D, Lucier C, Molloy R (2002) From solutions to symbiosis: Blending with your customers. Strategy Bus 27(2):38-43

Swart J, Henneberg S (2007) Dynamic knowledge nets - the 3C model. J Knowledge Manag 11(6):126-141

Tikkanen H, Kujula J, Artto K (2007) The marketing strategy of a project-based firm: The four portfolios framework. Ind Mark Manag 36:194-205

Tuli K, Kohli A, Bharadwaj S (2007) Rethinking customer solutions: From product bundles to relational processes. J Mark 71:1-17

Tufte E (1983) The visual display of quantitative information. Graphics Press, Cheshire, Ct.

Ward Y, Graves A (2004) A new costs management and accounting approach for lean enterprises. University of Bath School of Management working paper Series, No. 2004.05

Wasserman S, Faust K (1994) Social network analysis: Methods and applications. Cambridge University Press, Cambridge, UK

Weick KE (1995) Sensemaking in organizations. Sage, Thousand Oaks

Weick KE, Roberts KH (1993) Collective mind in organizations: Heedful interrelating on flight decks. Adm Sci Q 38:357-381

Wiley N (1988) The micro-macro problem in social theory. Sociol Theory 6:254-261

Womack JP, Jones DT (2005) Lean solutions. Simon Schuster

Womack JP, Jones DT, Roos D (1990) The machine that changed the world. Rawson Associates, New York

Zahra S, George G (2002) Absorptive capacity: A review, reconceptualization, and extension. Acad Manage Rev 27(2):185-203

Zuboff S (1989) In the age of the smart machine: the future of work and power. Heinemannss, Oxford 